\title{
Evaluation of Iron Bioavailability in Caco-2 cell Culture Model: Modification of the Original Method
}

\author{
Bahareh Nikooyeh $^{1}$, Tirang R. Neyestani*1 \\ 1- Laboratory of Nutrition Research, National Nutrition and Food Technology Research Institute and Faculty of Nutrition Sciences and Food \\ Technology, Shahid Beheshti University of Medical Sciences, Tehran, Iran
}

\section{A B S T R A C T}

Background and Objectives: In the original in vitro method for evaluation of iron bioavailability using caco-2 cell model, ferritin formation by cells is considered as a functional indicator of both absorption and utilization of iron. However, as iron is measured in the tested material and then ferritin concentration is measured in caco- 2 cell lysate, it is almost impossible to have a concrete measure of iron bioavailability because the percent of absorbable iron cannot be calculated by the concentration of iron in caco-2 cell lysate. To overcome this problem, the original method was modified by using ferrous sulfate tablet as a standard and also including blank well in the cell culture plate to subtract the baseline ferritin concentration from the ferritin concentration of other wells.

Materials and Methods: To evaluate iron bioavailability in this model, one kind of Iranian traditional breads (Sangak) was used. Standard curve was plotted using iron concentration and ferritin/protein ratio in the $\mathrm{X}$ and $\mathrm{Y}$ axes, respectively.

Results: The standard curve showed a linear equation: Ferritin $(\mathrm{ng}) /$ protein $(\mathrm{mg})=(5.96 \times$ bread Fe $)+11.55, \mathrm{R}^{2}=0.989$. Using this equation, the bioavailability of iron from the tested bread was $79.76 \pm 11.5 \%$ of ferrous sulfate. Considering that the reported iron bioavailability from ferrous sulfate is about $10 \%$, bioavailability of iron from the bread could be regarded $8 \%$.

Conclusions: This data can be potentially usable to adjust the amount of absorbable iron in the target population for fortification programs.

Keywords: Iron, Bioavailability, Caco-2 cell

\section{Introduction}

Iron deficiency is one of the most prevalent micronutrient deficiencies all around the world, including Iran (1). The World Health Organization (WHO) has estimated that some two billion people are affected by iron deficiency anemia (IDA). Despite the attempts made during the last two decades to eradicate this problem, it still persists, especially in the developing countries (2). Infants, preschool children, adolescents and especially girls and women in child-bearing years as well as pregnant women are vulnerable subpopulations (35). Iron deficiency (either with or without anemia) has many adverse health consequences for both children and adults. Infants born to anemic mothers are at greater risk of perinatal death. Impaired mental and physical functions can also occur due to iron deficiency. Factors contributing in iron deficiency are many including low intake from dietary sources, poor dietary habits, increased iron loss, repeated infections, and poor bioavailability of iron in foods. In the first National Investigation of Micronutrients Survey (NIMS), $14.5 \%$ of the Iranian adults of both sexes were found to have IDA. On the other hand, in the Comprehensive Household Food Consumption Survey (CHFCS) the per capita iron intake was reported $15 \mathrm{mg}$ a day. However, over $80 \%$ of dietary iron in Iran has plant origin, mostly from bread and cereals $(54.2 \%)$ (6), which are known to have less bioavailable iron as compared with the animal dietary sources.

To combat this problem, Iran Ministry of Health $(\mathrm{MOH})$ has implemented iron fortification of flour. However, no studies have been done so far to 
evaluate the availability of iron from the fortified breads.

Human studies of iron bioavailability are usually very expensive and may necessitate using tracer iron (7). Animal models could be suitable alternatives but they do not eliminate the need for radioisotope iron and their response might be different from that of humans (8). The need for a tracer iron is a very huge limitation for this sort of studies. The in vitro methods for evaluating iron bioavailability could be rapid and less expensive alternative. In one of the mostly used methods, gastric and intestinal digestion and absorption are simulated in vitro using caco-2 cell culture (9). In this method, ferritin formation by caco-2 cells is considered as a functional indicator of both absorption and utilization of iron in the tested material. However, as iron is measured in the tested material and then ferritin concentration is measured in caco- 2 cell lysate, it is almost impossible to have a concrete measure of iron bioavailability because the percent of absorbable iron cannot be calculated from the ferritin concentration of caco- 2 cell lysate. As a result, this method is commonly used to compare the bioavailability of iron from different food sources or to investigate the effects of enhancers and inhibitors (10-14). To overcome this problem, we modified the original method by making a standard curve of bioavailability using ferrous sulfate tablet and then comparing the bioavailability of the tested material to that of standard with similar iron concentration in the standard curve.

\section{Materials and Methods}

Preparation of standards: Ferrous sulfate tablet containing $50 \mathrm{mg}$ of elemental iron was crushed and made to the volume of $10 \mathrm{~mL}$ using double distilled water (DDW). From this stock solution $(500 \mathrm{mg} / \mathrm{dL})$, working solutions of $1.25,2.5$ and $5.0 \mathrm{mg} / \mathrm{dL}$ were prepared.

Sample preparation: In this study, we used one kind of Iranian traditional flat breads (Sangak) to set up the method. The bread samples were completely dried by keeping at $70{ }^{\circ} \mathrm{C}$ for $5.0 \mathrm{hrs}$. Then they were powdered using a blender, pooled and divided into five replicates.

In vitro digestion: One gram of each of the pooled samples or $1 \mathrm{~mL}$ of the working standards was transferred into clean acid-washed $15 \mathrm{~mL}$ screw cap tubes, and the $\mathrm{pH}$ was adjusted to 2 using $5.0 \mathrm{M} \mathrm{HCl}$. The whole remaining steps afterwards were similar for both samples and standards. To each $1.0 \mathrm{~mL}$ of sample, $0.05 \mathrm{~mL}$ freshly prepared pepsin (SigmaAldrich, porcine: cat no. P-7000) in $0.1 \mathrm{M} \mathrm{HCl}(800-$ 2500 units/mg protein) was added. The tubes were then kept on horizontal mixer at 55 oscillations $/ \mathrm{min}$ for $60 \mathrm{~min}$ at room temperature (RT). Then $0.1 \mathrm{~g}$ of pancreatin (Sigma-Aldrich, porcine: cat. No. P-1750) and $0.6 \mathrm{~g}$ of bile extract (deoxycholin-glycine, taurine and other bile salts conjugates) (SigmaAldrich, porcine: cat. No.B-8631) were dissolved in $50 \mathrm{~mL}$ of $0.1 \mathrm{M} \mathrm{NaHCO}_{3}$. To simulate the intestinal digestion, the sample's $\mathrm{pH}$ was adjusted to 7 using 1 $\mathrm{M} \mathrm{NaHCO}_{3}$ drip. Then $2.5 \mathrm{~mL}$ of fresh pancreatinbile extract was added to each $10 \mathrm{~mL}$ sample. The $\mathrm{pH}$ of this preparation was adjusted to 7.4 using $1 \mathrm{M}$ $\mathrm{NaOH}$, and the final volume was made to $15 \mathrm{~mL}$ using $120 \mathrm{mM} \mathrm{NaCl}$ and $5 \mathrm{mM} \mathrm{KCl} \mathrm{(1:1).}$

Cell culture and biochemical assays: Caco- 2 cells in passages 26-30 were purchased from Iran Pasteur Institute. The cells were transferred into a 6-well plate in $50,000 \mathrm{cell} / \mathrm{cm}^{2}$ in the same day of purchasing. Then they were incubated in Dulbecco's Modified Eagle Medium (DMEM, D7777) containing $10 \%$ fetal calf serum (FCS, Gibco, UK), and $1 \%$ antibiotic-antifungal mixture (SigmaAldrich, A5955) at $37{ }^{\circ} \mathrm{C}$ and $5 \% \mathrm{CO}_{2}$. The medium was changed every 2-3 days. The cells were, finally, used for bioavailability experiment after 14 days of incubation.

To prepare cells for iron uptake, the medium was removed from the well, and the cells were washed with $1 \mathrm{~mL}$ Hank's solution (Sigma-Aldrich) twice. Then they were covered with $1 \mathrm{~mL}$ DMEM. Dialysis membrane (cutoff: $15 \mathrm{kDa}$ ) was prepared by boiling in $1 \mathrm{mM} \mathrm{Na} \mathrm{CO}_{3}: 10 \mathrm{mM}$ EDTA $(1: 1, \mathrm{v} / \mathrm{v})$ for 30 minutes and then rinsing in DDW. An insert with a prepared dialysis membrane was put in each well making two chambers. $1.5 \mathrm{~mL}$ of the digest was transferred to the upper chamber. The samples and standards were tested in triplicates, and one well in each plate was used as blank by transferring DMEM instead of digest to the upper chamber of the well. The plate was lidded and incubated at $37^{\circ} \mathrm{C}$ and $5 \%$ $\mathrm{CO}_{2}$ for 120 minutes. Then the insert was removed and the cells were incubated under the same conditions again for $22 \mathrm{hrs}$. Then the cells, after removing the above solution, were washed with phosphate-buffered saline (PBS, pH 7.4) twice. After removing the washing buffer, the cells were harvested using $20 \mu \mathrm{L}$ trypsin $(0.2 \%$ trypsin in $0.5 \%$ EDTA). The harvested cells were suspended in $2 \mathrm{~mL}$ DDW and then centrifuged at $2000 \mathrm{~g}$ at RT for 10 minutes. The supernatant was discarded, and the 
sediment was re-suspended in $1 \mathrm{~mL} \mathrm{DWW}$. Then the suspended cells were crushed using 60 seconds homogenization at 20'000 rmp at RT (Heidolph, Silent Crusher M, Germany). The lysate was centrifuged for $10 \mathrm{~min}$ at $2000 \mathrm{~g}$ at RT. The supernatant was transferred to a clean microtube and kept at $-80{ }^{\circ} \mathrm{C}$ for further ferritin assay using the enzyme-linked immunosorbent assay (ELISA) (PishtazTeb, Tehran, IR).

Iron concentration in the samples was measured using spectrophotometric assay, which was shown to give comparable result with atomic absorption spectroscopy (15).
Protein concentration of the lysate was assayed using Bradford's method (16). The results were expressed as ng ferritin/mg protein. The standard curve was plotted using iron concentration and ferritin/protein ratio in the $\mathrm{X}$ and $\mathrm{Y}$ axes, respectively. Iron bioavailability from the bread was then estimated by comparing to that of standard with similar iron concentration in the standard curve. The linear equation was calculated using Excel 2013. The percent of iron bioavailability was calculated as: (ng ferritin/mg protein of the sample) $\div$ (ng ferritin/mg protein of the standard with same amount of iron) $\times 100$

Figure 1 shows the steps of the experiment.

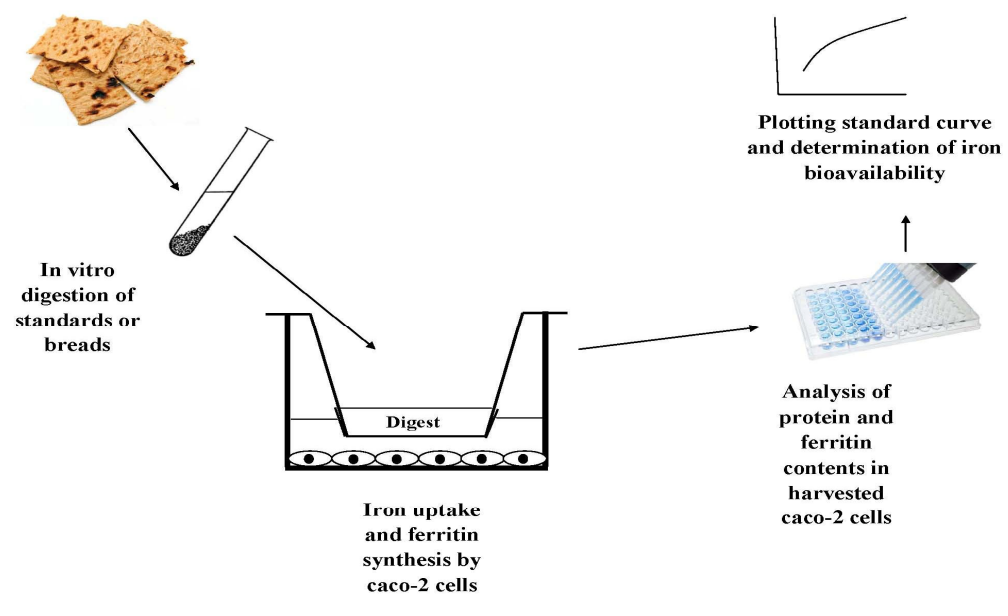

Figure 1. Steps of in vitro evaluation of iron bioavailability using caco-2 cell culture.

\section{Results}

Table 1 shows the amount of iron in different stages of the analysis. As $1 \mathrm{~g}$ of bread (containing $10.9 \mu \mathrm{g}$ iron) was digested and made to the final volume of $15 \mathrm{~mL}$, the initial concentration would be about $72.7 \mu \mathrm{g} / \mathrm{dL}$. Of this, some $67 \%$ was recovered in the digest. However, the concentration of iron decreased following dialysis down to $11 \mu \mathrm{g} / \mathrm{dL}$ equaling $15.2 \%$ of the initial amount of iron in the tested bread. Figure 2 demonstrates the standard curve, which shows a linear equation as follows:

$$
\text { Ferritin }(\text { ng }) / \text { protein }(\mathrm{mg})=(5.96 \times \text { bread Fe })+11.55, R^{2}=0.989
$$

Using this equation, the bioavailability of iron from the tested bread was $79.76 \pm 11.5 \%$ of ferrous sulfate. Considering that the bioavailability of iron from ferrous sulfate supplement is about $10 \%$ (17), the estimated bioavailability of iron from the tested bread could be regarded about $8 \%$.

Table 1. The amount of iron in different stages of the analysis

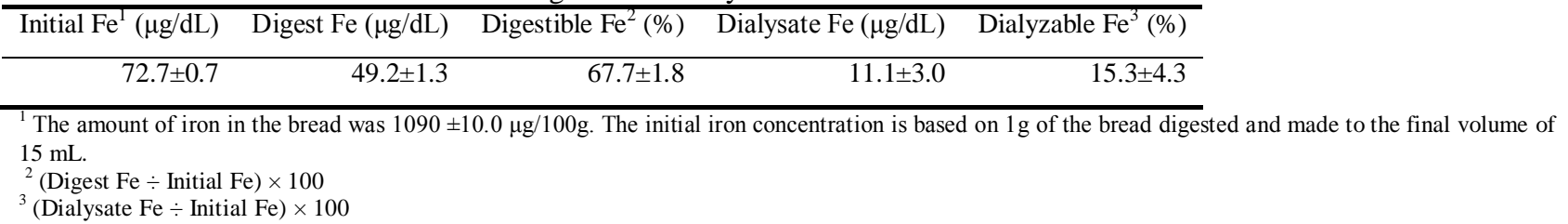




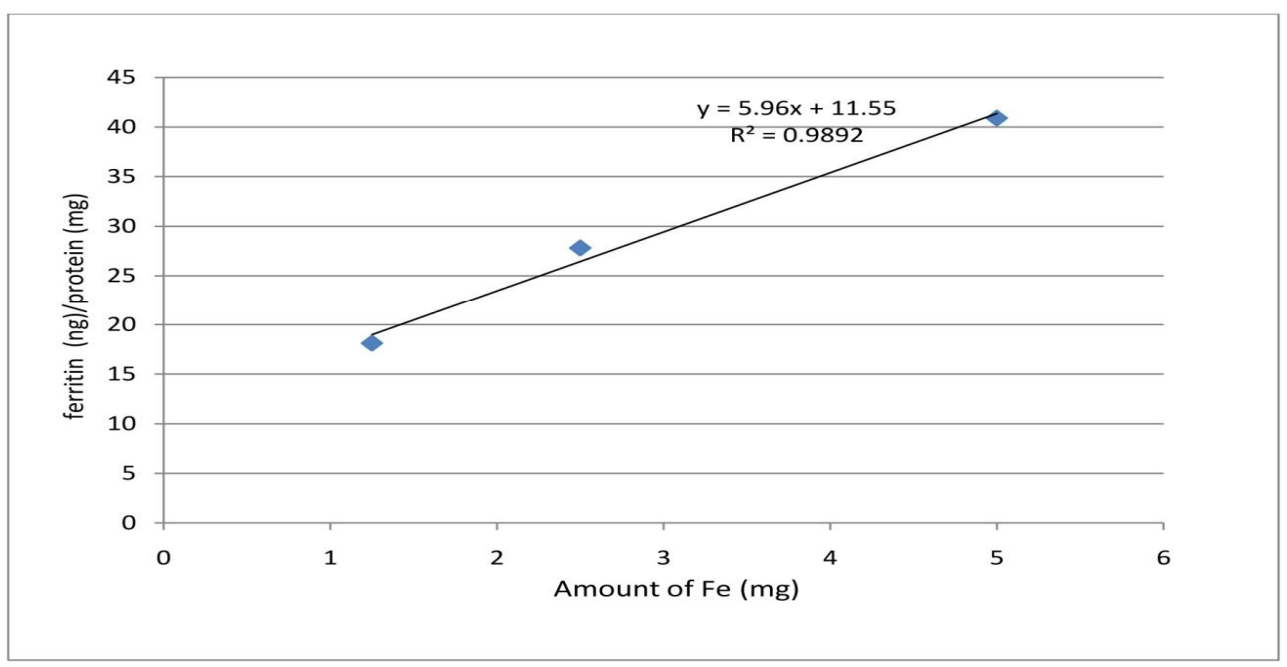

Figure 2. Standard curve of iron bioavailability using in vitro digestion and caco-2 cell model

\section{Disc ussion}

We used ferrous sulfate tablet as a standard to evaluate iron bioavailability from the tested food, i.e. one of the Iranian traditional flat bread (Sangak). This modification enabled us to determine the sensitivity of the method at different concentrations by plotting a standard curve and also to have a more tangible evaluation of iron bioavailability of the tested material. The range of reported non-heme iron bioavailability is very wide, from $0.7 \%$ to $22.9 \%$ (18). We found that the amount of iron in Sangak bread is relatively small but its bioavailability is rather high, $\sim 8 \%$. Traditionally, Sangak is baked by whole wheat flour, which is the only flour that is not currently fortified with iron in Iran.

The described original method was used to evaluate iron bioavailability from different food stuffs $(9,19)$. However, it is mostly employed to compare iron bioavailability from different dietary sources and to examine the effects of inhibitors or enhancers of iron absorption (12, 14, 20-24). While this new modification allows making an estimation of iron bioavailability from the tested food. Recently, iron bioavailability from different drug preparations was compared to ultra-pure powder of ferrous sulfate as a standard (25). However, the concentration of the standard was not reported. Besides, there is no data on iron bioavailability from ultra-pure ferrous sulfate powder, so no estimation of iron absorption from the tested materials could be made. Because of these, actually that method could not go beyond comparison of iron bioavailability among the preparations (25).

Dialyzability of iron has also been employed as a proxy to evaluate iron bioavailability from different food materials (26-28). We found that $15.3 \%$ of the initial iron in the tested bread was dialyzable. Though this percentage could be used to compare bioavailability of iron from different foods, it does not reveal the actual amount of the available iron. The amount of animal tissue, ascorbic acid, phytic acid, fiber and calcium in the tested food can all affect the actual amount of the dialyzable iron (27, 28).

Originally, sonication and scraping were used to crush and harvest cells from the wells (14). To minimize the harvesting error, we treated the cells by trypsin and then made a lysate by a homogenizer. Centrifugation of the lysate in the next step would give a clear solution, which is ideal for biochemical assay for ferritin. This modification has a further advantage of being remarkably less time-taking.

In the current study, for the first time, we included a blank well in each plate. In this modification, the concentrations of ferritin and protein were assayed, and the ferritin/protein ratio was calculated for the blank well and then subtracted from those of both standards and samples. The changes in the ferritin/protein ratios were, therefore, solely due to the treatment of the cells by standard or sample digests. 
Some limitations of this study should be acknowledged. In the current modified method, like any other in vitro methods, one of the most important determinants of iron bioavailability cannot be considered, which is the host iron status (29). Secondly, bioavailability of iron from a single food in an in vitro model may not necessarily be the same as in a mixed diet in the gastrointestinal tract.

However, similar to the original method, the modified method has a high precision and sensitivity with the advantage of making an estimation of the actual amount of absorbable iron from the tested food. This method can be employed to optimize the iron fortificant and also to adjust the amount of absorbable iron in the target population for further fortification program (30). Further studies are needed to examine if this modified method can be used to evaluate iron bioavailability from a mixed diet.

\section{Acknowledgement}

This study was a part of a research project conducted at NNFTRI. All laboratory bench works were performed at the Laboratory of Nutrition Research, NNFTRI. The caco-2 cells were provided from Iran Pasteur Institute.

\section{Financial disclosure}

The authors declared no financial interest.

\section{Funding/Support}

This research was financially supported in National Nutrition and Food Technology Research Institute and Faculty of Nutrition Sciences and Food Technology Research Institute (NNFTRI).

\section{References}

1. WHO/UNICEF/UNU. Iron Deficiency Anaemia. Assessment, Prevention and Control. A Guide for Progamme Managers (WHO/NHD/01.3). World Health Organization, Geneva, Switzerland. 2001.

2. Ramakrishnan U, Imhoff-Kunsch B. Anemia and iron deficiency in developing countries. Handbook of Nutrition and Pregnancy: Springer; 2008. p. 337-54.

3. Lutter CK. Iron deficiency in young children in lowincome countries and new approaches for its prevention. The Journal of Nutrition. 2008;138(12):2523-8.

4. Allen LH. Anemia and iron deficiency: effects on pregnancy outcome. The American journal of Clinical Nutrition. 2000;71(5):1280s-4s.

5. Neyestani T, Nikooyeh B, Hajifaraji M, Kalayi A. The prevalence of zinc deficiency and its relevance with iron status and economical living area in 9-12 year children. International J Vitamin Nutr Res. 2016; [in press].
6. Kalantari N, Ghafarpour, M. National Comprehensive Study on Household Food Consumption Pattern and Nutritional Status, IR Iran, 2001-2003. (National Report) 2005 .

7. Hulten L, Gramatkovski E, Gleerup A, Hallberg L. Iron absorption from the whole diet. Relation to meal composition, iron requirements and iron stores. Eur $\mathrm{J}$ Clin Nutr. 1995 Nov;49(11):794-808.

8. Reddy MB, Cook JD. Assessment of dietary determinants of nonheme-iron absorption in humans and rats. Am J Clin Nutr. 1991;54:723-8.

9. Gangloff MB, Glahn RP, Miller DD, Van Campen D. Assessment of iron availability using combined in vitro digestion and Caco-2 cell culture. Nutr Res. 1996;16:479-87.

10. Chi KY, Miller DD, Cheng Z, Glahn RP. Bioavailability of elemental iron powders in bread assessed with an in vitro digestion/Caco-2 cell culture model. Journal of Food Science. 2005;70(3).

11. Fairweather-Tait S, Lynch S, Hotz C, Hurrell R, Abrahamse L, Beebe S, et al. The usefulness of in vitro models to predict the bioavailability of iron and zinc: a consensus statement from the HarvestPlus expert consultation. Int J Vitam Nutr Res. 2005 Nov;75(6):3714.

12. Glahn RP, Lai C, Hsu J, Thompson JF, Van Campen DR. Decreased citrate improves iron availability from infant formula: Application of an in vitro digestion/Caco-2 cell culture model. J Nutr. 1998;128:257-64.

13. Glahn RP, Lee OA, Miller DD. In vitro digestion/Caco-2 cell culture model to determine optimal ascorbic acid to Fe ratio in rice cereal. J Food Sci. 1999;64:925-8.

14. Glahn RP, Rassier M, Goldman MI, Lee OA, Cha J. A comparison of iron availability from commercial iron preparations using an in vitro digestion/Caco-2 cell culture model. J Nutr Biochem. 2000;11:62-8.

15. Hosseinimehr S, J, Bagheri G, Gholipoor M, Mokarami H. Comparative Spectrophotometric and Atomic Absorption Determination of Iron Content in Wheat Flour. J Biol Sci. 2007;7(2):451-3.

16. Shono N, Baskaeva E. [Bradford's method of determining protein: application, advantages and disadvantages]. Laboratornoe Delo. 1988(4):4-7.

17. Nagpal J, Choudhury P. Iron formulations in pediatric practice. Indian Pediatrics. 2004;41(8):807-15.

18. Collings R, Harvey LJ, Hooper L, Hurst R, Brown TJ, Ansett J, et al. The absorption of iron from whole diets: A systematic review. Am J Clin Nutr. 2013 Jul;98(1):6581.

19. Alvarez-Hernandez X, Nichols GM, Glass J. Caco-2 cell line: A system for studying intesth al iron transport across epithelial cell monolayers. Biochimica et Biophysica Acta. 1991;1070:205-8. 
20. Glahn RP, Wien EM, Van Campen DR, Miller DD. Caco-2 cell iron uptake from meat and casein digests parallels in vivo studies: Use of a novel in vitro method for rapid estimation of iron bioavailability. Journal of Nutrition. 1996;126(1):332-9.

21. Glahn RP, Lee OA, Yeung A, Goldman MI, Miller DD. Caco-2 Cell Ferritin Formation Predicts Nonradiolabeled Food Iron Availability in an In Vitro Digestion/Caco-2 Cell Culture Model. J Nutr. 1998;128:1555-61.

22. Au AP, Reddy MB. Caco-2 Cells Can Be Used to Assess Human Iron Bioavailability from a Semipurified Meal. J Nutr. 2000;130:1329-34.

23. Glahn RP, Wortley GM, South PK, Miller DD. Inhibition of iron uptake by phytic acid, tannic acid, and $\mathrm{ZnCl2:} \mathrm{studies} \mathrm{using} \mathrm{an} \mathrm{in} \mathrm{vitro} \mathrm{digestion/Caco-2} \mathrm{cell}$ model. J Agric Food Chem. 2002;50:390-5.

24. Yeung CK, Glahn RP, Wu X, Liu RH, Miller DD. In vitro iron bioavailability and antioxidant activity of raisins. Journal of Food Science. 2003;68(2):701-5.

25. Zariwala MG, Somavarapu S, Farnaud S, Renshaw D. Comparison study of oral iron preparations using a human intestinal model. Sci Pharm. 2013 Dec;81(4):1123-39.

26. Kapsokefalou M, Alexandropoulou I, Komaitis M, Politis I. In vitro evaluation of iron solubility and dialyzability of various iron fortificants and of ironfortified milk products targeted for infants and toddlers. Int J Food Sci Nutr. 2005 Jun;56(4):293-302.

27. Reddy MB, Hurrell RF, Cook JD. Estimation of nonheme-iron bioavailability from meal composition. Am J Clin Nutr. 2000 Apr;71(4):937-43.

28. Bueno L, Freire de Carvalho Cunha S, Marchini J, S, Dutra de Oliveira J, E,. Iron Dialyzability in a Multiple Nutrient Formulation and Effect of the Addition of Separate Nutrients. Bsic Sci Med. 2012;1(4):19-22.

29. Hurrell R, Egli I. Iron bioavailability and dietary reference values. Am J Clin Nutr. 2010 May;91(5):1461S-7S.

30. Hurrell R. How to Ensure Adequate Iron Absorption from Iron-fortified Food. Nutr Rev. 2002;60(7):(II)S7S15. 